\title{
Intakes and adequacy of potentially important nutrients for cognitive development among 5-year-old children in the Seychelles Child Development and Nutrition Study
}

\author{
Alison J McAfee ${ }^{1, *}$, Maria S Mulhern ${ }^{1}$, Emeir M McSorley ${ }^{1}$, Julie MW Wallace ${ }^{1}$, \\ Maxine P Bonham ${ }^{2}$, Jude Faure ${ }^{3}$, Sarah Romain ${ }^{3}$, Christina Esther ${ }^{3}$, \\ Conrad F Shamlaye ${ }^{3}$, Gene E Watson ${ }^{4}$, Gary J Myers ${ }^{4}$, Thomas W Clarkson ${ }^{4}$, \\ Philip W Davidson ${ }^{4}$ and JJ Strain ${ }^{1}$ \\ ${ }^{1}$ Northern Ireland Centre for Food and Health (NICHE), School of Biomedical Sciences, University of Ulster, \\ Coleraine BT52 1SA, UK: ${ }^{2}$ Department of Nutrition and Dietetics, Monash University, Melbourne, Australia: \\ ${ }^{3}$ Ministry of Health, Victoria, Mahé, Republic of Seychelles: ${ }^{4}$ School of Medicine and Dentistry, University of \\ Rochester, Rochester, NY, USA
}

Submitted 12 August 2011: Accepted 4 January 2012: First published online 10 February 2012

\begin{abstract}
Objective: To assess the nutritional adequacy of Seychellois children in relation to nutrients reported to be important for cognitive development.

Design: Dietary intakes were assessed by $4 \mathrm{~d}$ weighed food diaries and analysed using dietary analysis software (WISP version $3 \cdot 0$; Tinuviel Software, UK). Individual nutrient intakes were adjusted to usual intakes and, in order to investigate adequacy, were compared with the UK Estimated Average Requirements for children aged 4-6 years.

Setting: Children 5 years old were followed up as part of the Seychelles Child Development Nutrition Study (SCDNS), located in the high-fish-consuming population of Mahé, Republic of Seychelles.

Subjects: Analysis was carried out on a sample of 229 children (118 boys, 111 girls). Results: Children consumed a diet of which fortified cereal and milk products contributed the most to nutrient intakes. The majority ( $\geq 80 \%$ ) of children met requirements for several nutrients important for child development including Fe, folate and Se. Adjusted dietary intakes of $\mathrm{Cu}, \mathrm{Zn}$, iodine, niacin and vitamin A were below the Estimated Average Requirement or Recommended Nutrient Intake. Mean adjusted energy intakes (boys $4769 \mathrm{~kJ} / \mathrm{d}(1139 \cdot 84 \mathrm{kcal} / \mathrm{d})$, girls $4759 \mathrm{~kJ} / \mathrm{d}(1137 \cdot 43 \mathrm{kcal} / \mathrm{d}))$ were lower than the estimated energy requirement (boys $5104 \mathrm{~kJ} / \mathrm{d}(1220 \mathrm{kcal} / \mathrm{d})$, girls $5042 \mathrm{~kJ} / \mathrm{d}(1205 \mathrm{kcal} / \mathrm{d})$ ) for $88 \%$ of boys and $86 \%$ of girls.

Conclusions: Nutrition was adequate for most children within the SCDNS cohort. Low intakes of some nutrients (including $\mathrm{Zn}$, niacin and vitamin $\mathrm{A}$ ) could reflect nutritional database inaccuracies, but may require further investigation. The study provides valuable information on the adequacy of intakes of nutrients which could affect the growth and development of Seychellois children.
\end{abstract}

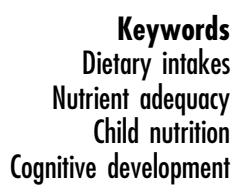

Keywords

Dietary intakes

Child nutrition

Cognitive development
Nutrition during early childhood has an important and long-lasting influence on child growth and cognitive development ${ }^{(1-3)}$. Brain growth and development is most rapid and critical during the first 2 years of life, but development of the frontal lobes continues throughout early childhood ${ }^{(4,5)}$. Certain nutrients make important contributions to optimum brain and neurological function including $\mathrm{Zn}$, Fe, iodine, folate, Se and long-chain PUFA $^{(5)}$. Many of these nutrients are involved in metabolic processes such as the production of enzymes or essential cofactors, some of which are central to brain growth and development ${ }^{(6,7)}$. $\mathrm{Zn}$ is recognised as important for growth and neurodevelopment, and low intakes have been associated with behavioural problems such as attention-deficit hyperactivity disorder in children ${ }^{(8)}$. Fe and iodine are critical nutrients in early brain development, but deficiencies are commonplace among school-aged children in both developing and developed countries and are a major cause of impaired motor skills and cognitive function ${ }^{(1,9)}$. Folate and vitamin $\mathrm{B}_{12}$ are necessary for the methylation pathway, an integral process to the synthesis of DNA and neurotransmitters, while Se contributes to thyroid hormone 
synthesis and may affect mood ${ }^{(1,6)}$. There is evidence that DHA ( $n$-3 PUFA) and arachidonic acid ( $n$ - 6 PUFA), longchain PUFA which are most important during fetal and infant development, can offer postnatal benefits to child performance and behaviour ${ }^{(10-12)}$.

A poor diet during childhood may be associated with low intakes of these nutrients and evidence from longitudinal studies suggests that dietary habits formed in childhood can often continue into later life ${ }^{(13,14)}$, thus highlighting the importance of assessing childhood diet. Assessment of nutrient adequacy, which has been defined as intake of nutrients which either meets or exceeds the appropriate Dietary Reference Value (DRV) for that population without being excessive ${ }^{(15)}$, is a useful tool in dietary surveys of children.

An additional interesting aspect of the relationship between nutrition and child development described by Strain et $\mathrm{l}^{(16)}$ is the suggestion that nutrients in fish may ameliorate the potentially neurotoxic effects of methylmercury exposure. This issue is of special concern within high-fish-eating populations such as the Republic of Seychelles. For this reason, the Seychelles Child Development Nutrition Study (SCDNS) is investigating nutritional intakes and status of pregnant women and their children. The aim of the current study was to analyse dietary intakes and investigate adequacy of potentially important nutrients for cognitive development among 5-year-old Seychellois children.

\section{Experimental methods}

\section{Participants}

The present study is a follow-up analysis of children born to mothers initially recruited for the SCDNS. In 2001, a total of 300 pregnant women were recruited within Mahé, the main island of the Republic of Seychelles. This cohort was considered representative of the Seychelles population owing to study design and recruitment, which have been described in detail previously ${ }^{(17)}$. As part of that longitudinal study, offspring of the women were re-evaluated in 2006 when they were approximately 5 years old. There were complete dietary data for a total of 229 children who participated in the follow-up study. The study was reviewed and approved by the appropriate Research Subjects Review Boards of collaborating partners, the Ministry of Health of Seychelles and the University of Rochester.

\section{Dietary assessment}

Dietary intakes were assessed using two weighed $4 \mathrm{~d}$ food diaries, of which one was supplied to parents/ guardians and the other to teachers, who were requested to keep records of each child's food intake over four consecutive days (two weekdays and two weekend days) when at home and at school. Diet diaries were available in both English and Creole languages. Both parents/ guardians and teachers were supplied with Ravenscourt weighing scales to assist with recording portion weights of food and drinks consumed by the children, including information on amount, brand, recipe and preparation method used. When it was not possible to weigh meals received at school, researchers and trained nutritionists in the Seychelles assisted with calculating portion sizes of meals eaten by the children during school hours. Nutritionists in the Seychelles reviewed the diaries within one week of completion, with any errors and omissions being clarified with children and their families. Researchers also visited the family home/school frequently to monitor the weighing and recording of foods by respective parents/ guardians and teachers. Food and nutrient intakes were analysed using the nutrient database package WISP version $3 \cdot 0$ (Tinuviel Software, Warrington, UK), which contains data from the UK Nutrient Databank ${ }^{(18)}$ and was previously supplemented with food composition and recipe data for foods typical to the Seychelles diet ${ }^{(19)}$. In the present study, the WISP database was further augmented with food composition data of foods commonly consumed by Seychellois children. Owing to incomplete PUFA composition data for all fish species, it was not possible to analyse PUFA intakes accurately within the study.

Dietary data were coded into seventeen food groups and expressed as $\mathrm{g} / \mathrm{d}$ : cereal \& cereal products; milk \& milk products; eggs; vegetables; fruit; sugars, preserves \& snacks; white fish; fatty fish; crustaceans; molluscs; fish products \& dishes; red meat; white meat; meat products \& dishes; fats and oils; beverages; and other foods (which included the sum of herbs \& spices, nuts \& seeds, soups, sauces \& miscellaneous foods). Fish were classified as being white (lean) or fatty based on knowledge of their total fat and fatty acid content ${ }^{(20)}$. For five children, dietary records were available only for three of the four surveyed days; therefore all calculations for these children were modified according to the three recorded days. Children's heights and weights were measured according to standardised procedures by nutritionists, using calibrated equipment at the Child Development Centre in Seychelles, and BMI was calculated as [weight $(\mathrm{kg})] /$ height $(\mathrm{m})]^{2}$.

\section{Assessing validity of energy intake}

In order to assess the validity of reported energy intake $\left(\mathrm{EI}_{\text {rep }}\right)$ in dietary surveys of children, it is important to use appropriate cut-offs for both age and sex in order to account for variability in growth and physical activity ${ }^{(21)}$. In the present study, the method described by Black and Cole $^{(22)}$ for evaluating energy intakes was employed. Energy expenditure (EE) was estimated using published sex- and age-specific equations which were developed using doubly labelled water data measured in children of a similar age ${ }^{(23)}$. 
A low active physical activity level (PAL $=1 \cdot 4-1 \cdot 6)$ was assumed for all children based on doubly labelled water data ${ }^{(24)}$, which allowed a constant corresponding physical activity coefficient value of $1 \cdot 16$ to be used in these equations. The estimated energy requirement (EER) was calculated as the $\mathrm{EE}+84 \mathrm{~kJ} / \mathrm{d}(20 \mathrm{kcal} / \mathrm{d})^{(23)}$. The validity of $\mathrm{EI}_{\text {rep }}$ was then assessed against $\mathrm{EE}$ by use of the $\mathrm{EI}_{\text {rep }}$ :EE ratio and by obtaining a $95 \%$ confidence limit for the agreement between these two measurements. In order to calculate the confidence limit, the within-subject $\mathrm{CV}$ for $\mathrm{EI}_{\text {rep }}$ and $\mathrm{EE}$ were initially calculated and the mean value for both the $\mathrm{CV}$ of $\mathrm{EI}_{\text {rep }}\left(\mathrm{CV}_{\mathrm{EI}}\right)$ and the $\mathrm{CV}$ of $\mathrm{EE}$ $\left(\mathrm{CV}_{\mathrm{EE}}\right)$, taken as $8 \cdot 2 \%$ for the present study ${ }^{(22)}$, were used to calculate a combined $\mathrm{CV}\left(\mathrm{CV}_{\mathrm{C}}\right)$ :

$$
\mathrm{CV}_{\mathrm{C}}=\sqrt{\left(\mathrm{CV}_{\mathrm{EE}}^{2}+\mathrm{CV}_{\mathrm{EI}}^{2}\right) / d}
$$

where $d$ is the number of days of dietary assessment. The acceptable range, or confidence limit, for $\mathrm{EI}_{\mathrm{rep}}$ :EE was then calculated as:

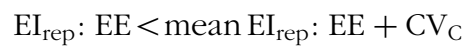

$$
\begin{aligned}
& \mathrm{EI}_{\text {rep }}: \mathrm{EE}>\text { mean }^{\mathrm{EI}_{\text {rep }}}: \mathrm{EE}-\mathrm{CV}_{\mathrm{C}}
\end{aligned}
$$

Those children with a ratio below this limit were then classified as under-reporters, while normal reporters were classified as those children with an $\mathrm{EI}_{\mathrm{rep}}$ :EE within the acceptable range.

\section{Assessment of nutritional adequacy}

Nutritional adequacy was evaluated by applying a statistical equation to adjust the distribution of nutrient intakes reported from the $4 \mathrm{~d}$ assessment period, thus correcting for intra-individual variability which creates inaccuracies in dietary assessment ${ }^{(25)}$. Adjusted nutrient intakes were then compared with the Estimated Average Requirement (EAR) according to UK DRV ${ }^{(25,26)}$ for healthy children of the same sex and age. In the absence of specific nutritional guidelines existing for the Seychelles population, the UK DRV have been used and these DRV are considered to be appropriate guidelines for this population ${ }^{(17)}$. The EAR is known as the best reference value with which to examine the prevalence of inadequate nutrient intakes within a group ${ }^{(23)}$. This method has been described as the most accurate compared with alternative methods of assessing nutrient adequacy $^{(27)}$. In the case of $\mathrm{Na}, \mathrm{K}, \mathrm{Cu}$, Se and iodine, the Recommended Nutrient Intake (RNI) has been used for comparison in the absence of an established EAR. The RNI, however, can only be used to estimate nutritional adequacy for intakes above, but not below, this level ${ }^{(25)}$. Furthermore, the EAR cut-point method cannot be used to assess energy intakes, as this approach would break a statistical assumption of the method, namely that the nutrient intake is not related to requirement ${ }^{(28)}$. Therefore we compared energy intakes against the group mean EER instead. Nutrient inadequacy was evaluated as the percentage of children with adjusted intakes below the EAR.

\section{Statistical analysis}

Statistical analyses were conducted using the SPSS for Windows statistical software package version 18.0 (SPSS Inc., Chicago, IL, USA). Data for all variables were initially tested for normality prior to analysis and descriptive data were expressed as means and standard deviations or medians and 5th, 95th percentiles as appropriate. Nutrient intakes were adjusted using a method described by Beaton $^{(29)}$, where within- and between-individual variations in nutrient intakes were calculated before applying the equation:

$$
\begin{aligned}
& \text { Adjusted nutrient intake }= \\
& \quad \text { (Individual mean intake }- \text { group mean intake }) \\
& \quad \times[\text { (SD individual/SD group })+\text { group mean intake }]
\end{aligned}
$$

These intakes were then compared with the UK EAR for each nutrient by calculating the percentage of children with intakes below this level. Independent $t$ tests and one-sample $t$ tests were used to determine differences in intakes between boys and girls and between the group including and excluding under-reporters, respectively. In all instances, a two-tailed $P$ value of $\leq 0.05$ was considered statistically significant.

\section{Results}

\section{Participant characteristics}

The group consisted of 118 boys and 111 girls. Their mean age was $5.62(\mathrm{SD} 0.31)$ years and their mean height and weight values $(1.15(\mathrm{sD} 0.05) \mathrm{m})$ and $19.99(\mathrm{sD} 3.79) \mathrm{kg}$ ) were above the 75th percentiles for height and weight according to the Seychelles growth curve data for children. The mean BMI of the boys $\left(15.05\right.$ (SD 1.97) $\mathrm{kg} / \mathrm{m}^{2}$ ) and girls $\left(15 \cdot 02(\mathrm{sD} 2 \cdot 08) \mathrm{kg} / \mathrm{m}^{2}\right)$ was between the 50 th and the 75th percentiles for BMI, placing them within the normal height for weight category for their age group. Using specific height and weight data for each child, the mean EE was estimated at 6121 (SD 586) $\mathrm{kJ} / \mathrm{d}(1463$ (SD 140$) \mathrm{kcal} / \mathrm{d}$ ). The mean $\mathrm{EI}_{\text {rep }}$ and daily variance in energy intake were 4841 (sD 1364) kJ/d (1157 (sD 326) $\mathrm{kcal} / \mathrm{d}$ ) and $27 \cdot 75 \%$, respectively, which gave a $95 \%$ confidence limit of the agreement between $\mathrm{EI}_{\text {rep }}$ :EE of $0 \cdot 63-0 \cdot 95$. According to this cut-off, $21 \%$ of children were classified as under-reporters ( $n$ 49) and $79 \%$ as normal reporters $(n$ 180).

\section{Energy and nutrient intakes}

Table 1 presents mean dietary intakes of energy and nutrients for the entire cohort ( $n$ 229) and separately for the group excluding under-reporters ( $n$ 180). When mean nutrient intakes were compared between these groups, intakes of energy, protein, fat, $\mathrm{K}, \mathrm{Zn}$ and thiamin were significantly higher $(P<0 \cdot 05)$ in the group which excluded under-reporters. Under-reporting did not have an effect on intake of any other nutrient and there were no 
Table 1 Estimated daily intakes of energy and nutrients showing the effect of dietary under-reporting among 5-year-old Seychellois children, Seychelles Child Development Nutrition Study (SCDNS), 2006

\begin{tabular}{|c|c|c|c|c|c|}
\hline \multirow[b]{2}{*}{ Nutrient } & \multicolumn{2}{|c|}{ Including under-reporters ( $n$ 229) } & \multicolumn{2}{|c|}{ Excluding under-reporters $(n 180)$} & \multirow[b]{2}{*}{$P^{*}$} \\
\hline & Mean & SD & Mean & SD & \\
\hline \multicolumn{6}{|l|}{ Energy } \\
\hline $\mathrm{kJ} / \mathrm{d}$ & 4839 & 1365 & 5240 & 1224 & 0.002 \\
\hline $\mathrm{kcal} / \mathrm{d}$ & $1156 \cdot 54$ & $326 \cdot 32$ & $1252 \cdot 35$ & $292 \cdot 59$ & 0.002 \\
\hline \multicolumn{6}{|l|}{ Macronutrients } \\
\hline Protein $(\mathrm{g} / \mathrm{d})$ & $39 \cdot 37$ & $11 \cdot 71$ & $42 \cdot 29$ & $11 \cdot 07$ & 0.004 \\
\hline Fat $(\% \mathrm{E})$ & $33 \cdot 27$ & $4 \cdot 83$ & 33.58 & 4.91 & 0.039 \\
\hline Carbohydrate (\%E) & $52 \cdot 06$ & $5 \cdot 32$ & $51 \cdot 85$ & $5 \cdot 25$ & 0.218 \\
\hline Fibre $(g / d)$ & $4 \cdot 38$ & 1.96 & $4 \cdot 71$ & 1.98 & 0.622 \\
\hline \multicolumn{6}{|l|}{ Minerals } \\
\hline $\mathrm{Na}(\mathrm{mg} / \mathrm{d})$ & $1535 \cdot 53$ & $1224 \cdot 97$ & $1668 \cdot 94$ & $1342 \cdot 06$ & 0.833 \\
\hline $\mathrm{K}(\mathrm{mg} / \mathrm{d})$ & $1191 \cdot 82$ & $377 \cdot 05$ & $1287 \cdot 13$ & $348 \cdot 70$ & 0.001 \\
\hline $\mathrm{Ca}(\mathrm{mg} / \mathrm{d})$ & $452 \cdot 72$ & $194 \cdot 85$ & $493 \cdot 50$ & $193 \cdot 23$ & 0.770 \\
\hline$M g(m g / d)$ & $113 \cdot 25$ & $37 \cdot 76$ & $123 \cdot 02$ & $35 \cdot 46$ & 0.058 \\
\hline $\mathrm{Fe}(\mathrm{mg} / \mathrm{d})$ & $6 \cdot 41$ & $2 \cdot 57$ & 6.96 & $2 \cdot 55$ & 0.930 \\
\hline $\mathrm{Cu}(\mathrm{mg} / \mathrm{d})$ & 0.53 & $0 \cdot 21$ & 0.57 & $0 \cdot 20$ & 0.941 \\
\hline $\mathrm{Zn}(\mathrm{mg} / \mathrm{d})$ & $4 \cdot 31$ & $1 \cdot 42$ & $4 \cdot 64$ & $1 \cdot 33$ & 0.044 \\
\hline Se $(\mu g / d)$ & 33.59 & $13 \cdot 19$ & $35 \cdot 48$ & $13 \cdot 49$ & 0.503 \\
\hline lodine $(\mu \mathrm{g} / \mathrm{d})$ & $61 \cdot 56$ & $29 \cdot 19$ & $66 \cdot 19$ & $29 \cdot 52$ & 0.286 \\
\hline \multicolumn{6}{|l|}{ Vitamins } \\
\hline Vitamin A $(\mu \mathrm{g} / \mathrm{d})$ & $222 \cdot 71$ & $148 \cdot 31$ & $245 \cdot 87$ & $157 \cdot 95$ & $0 \cdot 323$ \\
\hline Thiamin $(\mathrm{mg} / \mathrm{d})$ & 0.69 & 0.27 & 0.76 & 0.26 & 0.017 \\
\hline Riboflavin (mg/d) & 0.79 & 0.36 & $0 \cdot 86$ & 0.36 & 0.691 \\
\hline Niacin $(\mathrm{mg} / \mathrm{d})$ & $8 \cdot 46$ & $3 \cdot 21$ & $9 \cdot 13$ & $3 \cdot 13$ & $0 \cdot 180$ \\
\hline Vitamin $B_{6}(\mathrm{mg} / \mathrm{d})$ & 0.88 & $0 \cdot 32$ & 0.96 & 0.31 & 0.212 \\
\hline Folate $(\mu \mathrm{g} / \mathrm{d})$ & $135 \cdot 14$ & $59 \cdot 52$ & $147 \cdot 00$ & $59 \cdot 45$ & $0 \cdot 870$ \\
\hline Vitamin $B_{12}(\mu \mathrm{g} / \mathrm{d})$ & 2.04 & 0.85 & $2 \cdot 16$ & 0.79 & 0.274 \\
\hline Vitamin $C(\mathrm{mg} / \mathrm{d})$ & $66 \cdot 86$ & $37 \cdot 34$ & $71 \cdot 07$ & $37 \cdot 23$ & 0.452 \\
\hline Vitamin D $(\mu \mathrm{g} / \mathrm{d})$ & $2 \cdot 14$ & $1 \cdot 17$ & $2 \cdot 32$ & $1 \cdot 22$ & 0.676 \\
\hline Vitamin $E(\mathrm{mg} / \mathrm{d})$ & $6 \cdot 80$ & $2 \cdot 87$ & $7 \cdot 39$ & $2 \cdot 86$ & 0.476 \\
\hline
\end{tabular}

$\% \mathrm{E}$, percentage of total energy intake.

${ }^{\star} P<0.05$ indicates a significant difference in nutrient intakes between all children including under-reporters $(n$ 229) and children excluding under-reporters ( $n$ 180), as assessed by a one-sample $t$ test.

significant differences in nutrient intakes between boys and girls. We therefore carried out the following analyses of nutrient adequacy on the entire cohort ( $n$ 229) in order to include as many valid dietary entries as possible and because the detected degree of under-reporting impacted only some nutrient intakes.

\section{Nutrient adequacy}

Table 2 presents adjusted nutrient intakes for the entire cohort ( $n$ 229) and for boys ( $n$ 118) and girls ( $n$ 111) separately, showing the proportion with inadequate intakes below the UK EAR. Although only adult guideline intakes exist for total fat and carbohydrate (33\% and $47 \%$ of daily energy) within the UK DRV, adjusted mean intakes of all children met these guidelines. Every child met recommended protein requirements, while $\geq 86 \%$ of children were deemed as having adequate intakes of many nutrients, namely $\mathrm{K}, \mathrm{Ca}, \mathrm{Mg}, \mathrm{Fe}$, Se, thiamin, riboflavin, folate and vitamins $B_{12}$ and $C$. Adjusted mean energy intakes of boys (4769 (sD 524) kJ/d (1139.84 (sD 125.15) kcal/d)) and girls (4759 (sD 633) kJ/d (1137.43 (SD 151.41) kcal/d)) fell below the EER by 439 and $423 \mathrm{~kJ} / \mathrm{d}$ (105 and $101 \mathrm{kcal} / \mathrm{d})$, respectively. Compared with the EAR, $\geq 92 \%$ of children were found to have inadequate intakes of $\mathrm{Zn}$, vitamin $\mathrm{A}$ and niacin and a further $30 \%$ of boys and $23 \%$ of girls, respectively, had vitamin $\mathrm{B}_{6}$ intakes below the EAR. A large proportion of children $(\geq 86 \%$ ) were found to have intakes below the RNI for $\mathrm{Cu}$ and iodine. The RNI for vitamin D among this age group is set at zero, as it is expected that children's requirements will be met through exposure to sunlight ${ }^{(30)}$. Adequacy of vitamin $\mathrm{E}$ intakes was also not assessed in this age group given that there exists only a safe intake level for vitamin $\mathrm{E}$ for infants in the $\mathrm{UK}^{(26)}$. There were no significant differences in the number of children with inadequate intakes between boys and girls; however, adjusted mean intakes of vitamin $\mathrm{E}$ were significantly greater in girls than boys $(P=0 \cdot 05)$.

\section{Consumption of food groups and contribution to nutrient intakes}

Table 3 shows the children's reported daily intake of food groups and the contribution of food groups to energy, protein and nutrients which are potentially important for cognitive development. Children consumed most food groups, with cereal products, milk products and fruit being the major food groups in the diet for all consumers. These food groups were consumed by children in daily 
Table 2 Adjusted energy and nutrient intakes compared with the UK EAR as a cut-off point for assessing nutrient adequacy among 5-year-old Seychellois children, Seychelles Child Development Nutrition Study (SCDNS), 2006

\begin{tabular}{|c|c|c|c|c|c|c|c|c|c|}
\hline \multirow[b]{2}{*}{ Nutrient } & \multicolumn{2}{|c|}{ All ( $n$ 229) } & \multicolumn{2}{|c|}{ Boys ( $n$ 118) } & \multicolumn{2}{|c|}{ Girls (n 111) } & \multirow[b]{2}{*}{ UK EAR* ${ }^{*}$} & \multicolumn{2}{|c|}{$\%$ with intakes below the EAR } \\
\hline & Mean & SD & Mean & SD & Mean & SD & & Boys (n 118) & Girls (n 111) \\
\hline \multicolumn{10}{|l|}{ Energy } \\
\hline $\mathrm{kJ} / \mathrm{d}$ & 4764 & 578 & 4769 & 524 & 4759 & 633 & $\begin{array}{l}\text { Boys: } 5104 \\
\text { Girls: } 5042\end{array}$ & 88 & 86 \\
\hline $\mathrm{kcal} / \mathrm{d}$ & $1138 \cdot 67$ & $138 \cdot 19$ & $1139 \cdot 84$ & $125 \cdot 15$ & $1137 \cdot 43$ & $151 \cdot 41$ & $\begin{array}{l}\text { Boys: } 1220 \\
\text { Girls: } 1205\end{array}$ & 88 & 86 \\
\hline \multicolumn{10}{|l|}{ Macronutrients } \\
\hline Protein (g/d) & $39 \cdot 52$ & $4 \cdot 53$ & $39 \cdot 57$ & $5 \cdot 06$ & $39 \cdot 48$ & $3 \cdot 90$ & $14 \cdot 80$ & 0 & 0 \\
\hline Fat $(\% E)+$ & $33 \cdot 47$ & $2 \cdot 38$ & $33 \cdot 18$ & $1 \cdot 48$ & $33 \cdot 77$ & 3.03 & $33 \cdot 00$ & - & - \\
\hline Carbohydrate (\%E)† & 51.98 & $2 \cdot 16$ & $52 \cdot 17$ & $1 \cdot 81$ & $51 \cdot 77$ & $2 \cdot 46$ & $47 \cdot 00$ & - & - \\
\hline Fibre $(g / d) \dagger$ & $4 \cdot 28$ & 1.02 & $4 \cdot 33$ & 1.05 & $4 \cdot 22$ & 0.97 & $18 \cdot 00$ & - & - \\
\hline \multicolumn{10}{|l|}{ Minerals } \\
\hline $\mathrm{Na}(\mathrm{mg} / \mathrm{d}) \ddagger$ & $1365 \cdot 28$ & $949 \cdot 19$ & $1351 \cdot 89$ & $524 \cdot 58$ & $1379 \cdot 52$ & $1254 \cdot 75$ & $700 \cdot 00$ & 8 & 10 \\
\hline $\mathrm{K}(\mathrm{mg} / \mathrm{d}) \ddagger$ & $1186 \cdot 85$ & $145 \cdot 23$ & $1185 \cdot 53$ & $139 \cdot 14$ & $1188 \cdot 25$ & $152 \cdot 06$ & $1100 \cdot 00$ & 14 & 12 \\
\hline $\mathrm{Ca}(\mathrm{mg} / \mathrm{d})$ & $437 \cdot 69$ & $117 \cdot 18$ & $432 \cdot 38$ & $139 \cdot 97$ & $443 \cdot 25$ & 86.93 & $350 \cdot 00$ & 9 & 13 \\
\hline$M g(m g / d)$ & $108 \cdot 94$ & $27 \cdot 73$ & $108 \cdot 66$ & $32 \cdot 31$ & $109 \cdot 24$ & 21.99 & $90 \cdot 00$ & 9 & 12 \\
\hline $\mathrm{Fe}(\mathrm{mg} / \mathrm{d})$ & $6 \cdot 26$ & $1 \cdot 61$ & $6 \cdot 18$ & 1.99 & $6 \cdot 34$ & $1 \cdot 06$ & $4 \cdot 70$ & 8 & 6 \\
\hline $\mathrm{Cu}(\mathrm{mg} / \mathrm{d}) \ddagger$ & 0.51 & $0 \cdot 14$ & 0.51 & $0 \cdot 13$ & 0.51 & $0 \cdot 15$ & $0 \cdot 60$ & 88 & 86 \\
\hline $\mathrm{Zn}(\mathrm{mg} / \mathrm{d})$ & $4 \cdot 31$ & 0.57 & $4 \cdot 33$ & 0.69 & $4 \cdot 29$ & 0.41 & $5 \cdot 00$ & 92 & 96 \\
\hline $\operatorname{Se}(\mu \mathrm{g} / \mathrm{d}) \ddagger$ & $33 \cdot 50$ & $6 \cdot 93$ & $33 \cdot 27$ & $7 \cdot 83$ & $33 \cdot 75$ & $5 \cdot 85$ & $20 \cdot 00$ & 2 & 4 \\
\hline lodine $(\mu \mathrm{g} / \mathrm{d}) \ddagger$ & $59 \cdot 38$ & $19 \cdot 48$ & $59 \cdot 41$ & $23 \cdot 40$ & $59 \cdot 35$ & $14 \cdot 28$ & $100 \cdot 00$ & 98 & 100 \\
\hline \multicolumn{10}{|l|}{ Vitamins } \\
\hline Vitamin A $(\mu \mathrm{g} / \mathrm{d}) \S$ & $211 \cdot 05$ & $105 \cdot 55$ & $217 \cdot 55$ & 99.99 & $204 \cdot 15$ & $111 \cdot 18$ & $300 \cdot 00$ & 94 & 95 \\
\hline Thiamin $(\mathrm{mg} / \mathrm{d})$ & 0.69 & 0.11 & 0.69 & 0.12 & 0.69 & $0 \cdot 10$ & 0.30 & 1 & 1 \\
\hline Riboflavin (mg/d) & 0.74 & 0.59 & 0.72 & $0 \cdot 82$ & $0 \cdot 76$ & $0 \cdot 18$ & 0.60 & 11 & 11 \\
\hline Niacin $(\mathrm{mg} / \mathrm{d}) \|$ & $8 \cdot 39$ & $1 \cdot 48$ & $8 \cdot 48$ & $1 \cdot 29$ & $8 \cdot 29$ & $1 \cdot 64$ & $11 \cdot 00$ & 97 & 96 \\
\hline Vitamin $B_{6}(\mathrm{mg} / \mathrm{d})$ & $0 \cdot 86$ & $0 \cdot 17$ & 0.85 & $0 \cdot 18$ & 0.87 & $0 \cdot 15$ & 0.90 & 30 & 23 \\
\hline Folate $(\mu \mathrm{g} / \mathrm{d})$ & $131 \cdot 93$ & $34 \cdot 55$ & $132 \cdot 61$ & $3 \cdot 85$ & $131 \cdot 21$ & $35 \cdot 42$ & $100 \cdot 00$ & 9 & 9 \\
\hline Vitamin $B_{12}(\mu \mathrm{g} / \mathrm{d})$ & $2 \cdot 04$ & 0.43 & 2.08 & 0.49 & 1.99 & 0.37 & $0 \cdot 80$ & 2 & 1 \\
\hline Vitamin $C(\mathrm{mg} / \mathrm{d})$ & $54 \cdot 98$ & $95 \cdot 10$ & $49 \cdot 65$ & $127 \cdot 54$ & $60 \cdot 65$ & $37 \cdot 17$ & $30 \cdot 00$ & 11 & 8 \\
\hline Vitamin D $(\mu \mathrm{g} / \mathrm{d})$ & $2 \cdot 09$ & 0.67 & $2 \cdot 14$ & 0.74 & $2 \cdot 05$ & 0.59 & 0.00 & - & - \\
\hline Vitamin $E(\mathrm{mg} / \mathrm{d})$ & $6 \cdot 86$ & $1 \cdot 21$ & $6 \cdot 71^{a}$ & $1 \cdot 32$ & $7 \cdot 03^{b}$ & $1 \cdot 07$ & - & - & - \\
\hline
\end{tabular}

EAR, Estimated Average Requirement; \%E, percentage of total energy intake.

${ }_{\mathrm{a}, \mathrm{b}}$ Mean values within a row with unlike superscript letters were significantly different between boys and girls, as assessed by independent-samples $t$ test $(P=0.05)$.

*For energy, the estimated energy requirement (EER) is given based on the children's sex, age, height, weight and activity level.

tPopulation guide for adults only.

fUK Recommended Nutrient Intake in the absence of an EAR.

$\$$ As retinol equivalents.

$\|$ As niacin equivalents.

median (5th, 95th percentile) quantities of $56 \cdot 25(33 \cdot 97$, 98.74), $60.83(0,151 \cdot 00)$ and $70.58(0,198.67) \mathrm{g} / \mathrm{d}$, respectively. All children consumed vegetables, with a daily median (5th, 95 th percentile) amount of $23 \cdot 19(9 \cdot 42$, $76 \cdot 28) \mathrm{g} / \mathrm{d}$. Noticeably, fatty fish and white meat, of which chicken was the major component, were consumed in similar quantities (median (5th, 95th percentile): 26.00 $(0,77 \cdot 00)$ and $33 \cdot 50(0,120 \cdot 75) \mathrm{g} / \mathrm{d})$ by a similar proportion of children (74\% and $78 \%)$ and provided similar amounts of protein ( $8 \%$ and $9 \%)$, respectively. Cereal products and milk products contributed the largest amounts of energy, protein and nutrients to the diet, and the most commonly consumed cereal and milk products were white rice and cheddar cheese. These two food groups combined provided over $50 \%$ of $\mathrm{Fe}, \mathrm{Cu}, \mathrm{Zn}$, iodine and folate intakes. Vegetables also provided at least $10 \%$ of $\mathrm{Fe}, \mathrm{Cu}$, vitamin $\mathrm{B}_{6}$ and folate intakes. The median daily fatty fish consumption of $26.00 \mathrm{~g} / \mathrm{d}$ provided $14 \%$ of Se intake and $10 \%$ of vitamin $\mathrm{B}_{12}$ intake.

\section{Discussion}

The present study is the first report of dietary intakes of young children living in the Republic of Seychelles and shows that the diet of 5 -year-old children within the SCDNS provides adequate amounts of $\mathrm{Ca}, \mathrm{Mg}, \mathrm{Fe}$, Se, folate and vitamin $\mathrm{B}_{12}$. These nutrients are recognised as important for growth and development in children ${ }^{(1,31,32)}$ and suggest that this group of children in Seychelles, unlike those in many other countries ${ }^{(33-35)}$, are not at risk of impaired cognitive development caused by Fe-deficiency anaemia. Furthermore, their diet provides sufficient intakes of folate and vitamin $\mathrm{B}_{12}$, which are necessary to maintain neurological integrity ${ }^{(5)}$. An adequate Se intake may also have benefits for child development based on evidence that it can protect against possible neurotoxic effects of methylmercury to which all fish-eating populations are exposed $^{(36)}$. Given the children's frequent consumption of cereal products and milk products, fruits, vegetables and 


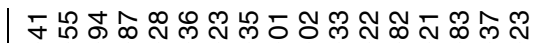

O் ல

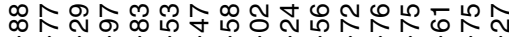

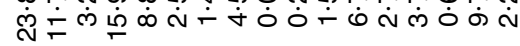

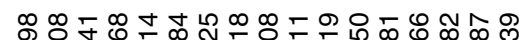

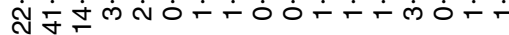

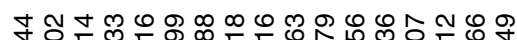

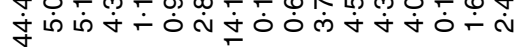

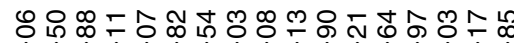

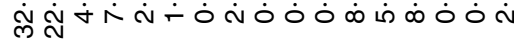

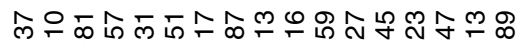

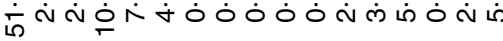

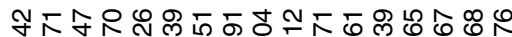

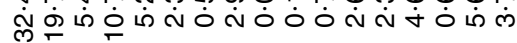

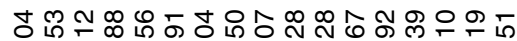

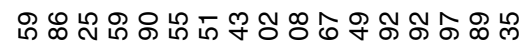
ம்ள்

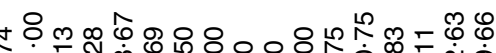

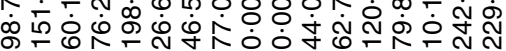

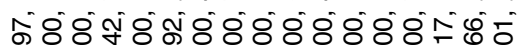

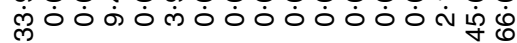

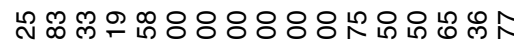

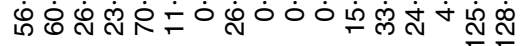

0
$\overline{0}$
$\frac{0}{5}$
0
0
0
0
0
0
0

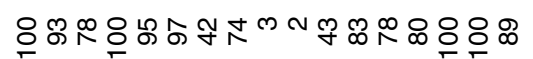

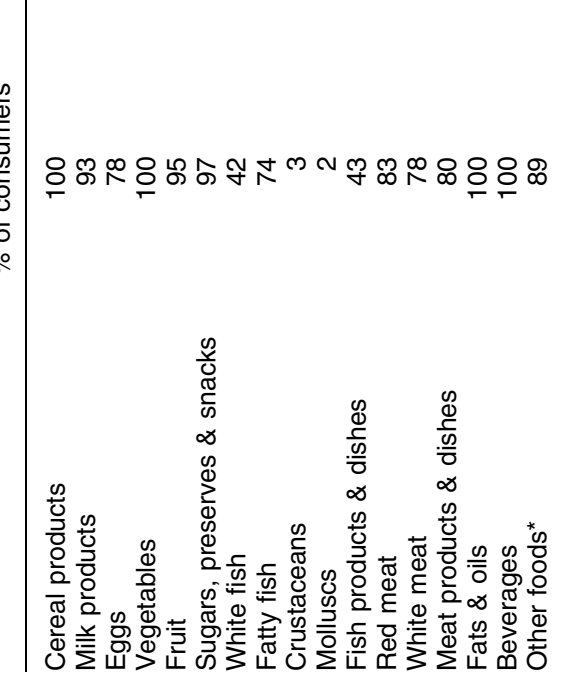

fish, one might expect these children to meet the EAR for this range of micronutrients. Cereal products, including rice and fortified breakfast cereals, were the largest contributors to intakes of $\mathrm{Fe}$, Se and folate in this cohort, as has been reported in other populations ${ }^{(37,38)}$. Milk products were the second largest contributing food group to nutrients, not surprisingly as milk imported to Seychelles is powdered and fortified with these micronutrients.

Reported energy intakes among $\geq 86 \%$ of boys and girls in this cohort were approximately $418 \mathrm{~kJ} / \mathrm{d}(100 \mathrm{kcal} / \mathrm{d})$ below the mean EER, suggesting that children were not eating enough to meet their energy requirements. These intakes are lower than energy intakes reported for children of a similar age living in European countries and the developing country of Papua New Guinea ${ }^{(35,39)}$. Bovet et al. ${ }^{(40)}$ previously reported that underweight was common among Seychellois children, with approximately $20 \%$ of boys and girls attending public schools being classed as grade 1 thinness according to international standards ${ }^{(41)}$. Despite an overall rise in the prevalence of obesity and overweight in Seychelles ${ }^{(42)}$, it is possible that underweight and associated low energy intakes are still an issue among young children. Subsequent follow-up of these children would be required to determine whether the low energy intakes reported by the present study compromise children's growth.

While many nutrients were found to be consumed in adequate amounts, at least $80 \%$ of children had suboptimal intakes of $\mathrm{Zn}$, vitamin $\mathrm{A}$ and niacin, and a further $23 \%$ of girls and $30 \%$ of boys were not meeting recommended intakes of vitamin $\mathrm{B}_{6}$. Deficiency of vitamin A can affect visual development and growth ${ }^{(43)}$, deficiency of niacin can affect psychological functions ${ }^{(32)}$ and deficiency of $\mathrm{Zn}$ is associated with poor attention span and impaired motor development ${ }^{(44)}$. For a large proportion of children reported $\mathrm{Cu}$ and iodine intakes were also below the RNI; however, in the absence of an EAR these low intakes cannot be interpreted as inadequacies ${ }^{(25)}$, but neither should they be disregarded based on the essential role of iodine in neurodevelopment ${ }^{(9)}$. While it is likely that the low energy intakes detected in this cohort could account for these low nutrient intakes, it is also possible that the UK DRV are not appropriate standards with which to compare dietary intakes of Seychellois children. It was particularly unexpected that Seychellois children would have low intakes of the above nutrients in view of their average fish consumption of $42 \mathrm{~g} / \mathrm{d}$; an intake which is notably higher than the UK total fish intake of $20 \mathrm{~g} / \mathrm{d}$ among $4-10$-year-olds ${ }^{(38,45)}$. Fish is rich in many nutrients including iodine, $\mathrm{Zn}, \mathrm{Cu}$, vitamin $\mathrm{A}$ and $n-3$ long-chain PUFA ${ }^{(46)}$. However, the intakes of several nutrients in the present study could have been underestimated as a result of incomplete nutrient composition data in the current nutritional database for all fish species consumed in Seychelles ${ }^{(17)}$. Indeed, for this same reason, it was not possible to investigate long-chain 
PUFA intakes in the current study. This possible underestimation should also be taken into consideration when interpreting the low intakes of some nutrients found in the present study.

Several steps were taken in our study to reduce the limitations which can be associated with dietary assessment in children ${ }^{(47)}$ and to strengthen the validity of the data presented, including the use of weighing scales to measure portion size and the statistical techniques used to detect dietary under-reporting and to remove intraindividual variability in nutrient intake. However, it was not possible to weigh all school meals consumed and although portion sizes for children were calculated and used in this instance, this approach may have impacted or affected the accuracy of dietary values obtained. The lack of specific DRV for the Seychelles may also be considered a potential limitation of the present study. As this cohort continues to be longitudinally assessed within the SCDNS, it would be of interest for future research to assess if these patterns of nutrient intake persist as children age and whether they are related to cognitive measures in these children.

Overall, the results of the present study indicate that this group of 5-year-old children in the Seychelles has adequate intakes of many nutrients deemed to be important for growth and cognitive development (protein, $\mathrm{Ca}, \mathrm{Mg}$, $\mathrm{Fe}$, Se and $\mathrm{B}$ vitamins). Intakes of energy, $\mathrm{Zn}$, vitamin $\mathrm{A}$ and niacin were found to be below this age group's requirements, but this may possibly reflect inaccuracies in our nutritional database. These findings on nutrient intakes of this group of children within the SCDNS should be valuable from a public health perspective with regard to implementing nutritional guidelines for children in the Seychelles population.

\section{Acknowledgements}

This study was supported by the US National Institute of Environmental Health Sciences, National Institutes of Health (grants 5-R01-ES010219, R01-ES015578 and 2-T32-ES007271); the European Union (contract EU FP62004-FOOD-3-A PHIME, Public Health Impact of longterm, low-level Mixed Element Exposure in susceptible population strata); and by the Government of Seychelles. There are no conflicts of interest. A.J.M. prepared the manuscript and analysed the dietary data. M.S.M. and M.P.B contributed to the dietary analysis. M.P.B., E.M.M., C.E., S.R. and J.F. collected and reviewed dietary data in the Seychelles. T.W.C., G.J.M., P.W.D., C.F.S., J.M.W.W. and J.J.S. were responsible for the study design. All authors read the manuscript and contributed to its finalisation. The authors thank Juliette Henderson and nurses at the Ministry of Health for all their work with the participants in the Seychelles, and also acknowledge the participation of all study participants involved.

\section{References}

1. Benton D (2010) The influence of dietary status on the cognitive performance of children. Mol Nutr Food Res $\mathbf{5 4}$, 457-470.

2. Feinstein L, Sabates R, Sorhaindo A et al. (2008) Dietary patterns related to attainment in school: the importance of early eating patterns. J Epidemiol Community Health 62, 734-739.

3. Northstone K \& Emmett PM (2008) Are dietary patterns stable throughout early and mid-childhood? A birth cohort study. Br J Nutr 100, 1069-1076.

4. Myers GJ, Thurston SW, Pearson AT et al. (2009) Postnatal exposure to methyl mercury from fish consumption: a review and new data from the Seychelles Child Development Study. Neurotoxicology 30, 338-349.

5. Bryan J, Osendarp S, Hughes D et al. (2004) Nutrients for cognitive development in school-aged children. Nutr Rev 62, 295-306.

6. Bourre JM (2006) Effects of nutrients (in food) on the structure and function of the nervous system: update on dietary requirements for brain. Part 2: macronutrients. J Nutr Health Aging 10, 386-399.

7. Benton D (2001) Micro-nutrient supplementation and the intelligence of children. Neurosci Biobehav Rev 25, 297-309.

8. DiGirolamo AM, Ramirez-Zea M, Wang M et al. (2010) Randomized trial of the effect of zinc supplementation on the mental health of school-age children in Guatemala. Am J Clin Nutr 92, 1241-1250.

9. Melse-Boonstra A \& Jaiswal N (2010) Iodine deficiency in pregnancy, infancy and childhood and its consequences for brain development. Best Pract Res Clin Endocrinol Metab 24, 29-38.

10. Ryan AS, Astwood JD, Gautier S et al. (2010) Effects of long-chain polyunsaturated fatty acid supplementation on neurodevelopment in childhood: a review of human studies. Prostaglandins Leukot Essent Fatty Acids 82, 305-314.

11. Zhang J, Hebert JR \& Muldoon MF (2005) Dietary fat intake is associated with psychosocial and cognitive functioning of school-aged children in the United States. J Nutr 135, 1967-1973.

12. McNamara RK, Able J, Jandacek R et al. (2010) Docosahexaenoic acid supplementation increases prefrontal cortex activation during sustained attention in healthy boys: a placebo-controlled, dose-ranging, functional magnetic resonance imaging study. Am J Clin Nutr 91, 1060-1067.

13. Mikkila V, Rasanen L, Raitakari OT et al. (2005) Consistent dietary patterns identified from childhood to adulthood: the cardiovascular risk in Young Finns Study. Br J Nutr $\mathbf{9 3}$, 923-931.

14. Mikkila V, Rasanen L, Raitakari OT et al. (2004) Longitudinal changes in diet from childhood into adulthood with respect to risk of cardiovascular diseases: The Cardiovascular Risk in Young Finns Study. Eur J Clin Nutr 58, 1038-1045.

15. National Research Council (1986) Nutrient Adequacy. Assessment Using Food Composition Surveys. Washington, DC: National Academy Press.

16. Strain JJ, Bonham MP, Duffy EM et al. (2004) Nutrition and neurodevelopment: the search for candidate nutrients in the Seychelles Child Development Nutrition Study. Seychelles Med Dent J 7, 77-83.

17. Bonham MP, Duffy EM, Robson PJ et al. (2009) Contribution of fish to intakes of micronutrients important for fetal development: a dietary survey of pregnant women in the Republic of Seychelles. Public Health Nutr 12, 1312-1320.

18. Food Standards Agency (2002) McCance and Widdowson's The Composition of Foods, 6th revised ed. [S Church, editor]. Cambridge: Royal Society of Chemistry.

19. Robson PJ, Bonham MP, Duffy EM et al. (2004) Development and implementation of a method to assess food and 
nutrient intakes in the Seychelles Child Development Study. Seychelles Med Dent J 7, 100-107.

20. Scientific Advisory Committee on Nutrition, Committee on Toxicology (2004) Advice on Fish Consumption: Benefits and Risks. London: The Stationery Office; available at http://cot.food.gov.uk/pdfs/fishreport2004full.pdf

21. Zlotkin SH (1996) A review of the Canadian 'Nutrition recommendations update: dietary fat and children'. J Nutr 126, 4 Suppl., 1022S-1027S.

22. Black AE \& Cole TJ (2000) Within- and between-subject variation in energy expenditure measured by the doublylabelled water technique: implications for validating reported dietary energy intake. Eur J Clin Nutr 54, 386-394.

23. Institute of Medicine of the National Academies, Food and Nutrition Board (2005) Dietary Reference Intakes for Energy, Carbohydrate, Fiber, Fat and Fatty Acids, Cholesterol, Protein and Amino Acids. Washington, DC: National Academies Press.

24. Rennie KL, Jebb SA, Wright A et al. (2005) Secular trends in under-reporting in young people. Br J Nutr 93, 241-247.

25. Institute of Medicine (2000) Specific Applications: Assessing Nutrient Intakes of Groups Using the Dietary Reference Intakes. Washington, DC: National Academies Press.

26. Department of Health (1991) Report of the Panel on Dietary Reference Values of the Committee on Medical Aspects of Food Policy. London: The Stationery Office.

27. Tabacchi G, Wijnhoven TM, Branca F et al. (2009) How is the adequacy of micronutrient intake assessed across Europe? A systematic literature review. Br J Nutr 101, Suppl. 2, S29-S36.

28. Gibson RS (2005) Principles of Nutritional Assessment, 2nd ed. New York: Oxford University Press.

29. Beaton GH (1994) Criteria of an adequate diet. In Modern Nutrition in Health and Disease, pp. 1491-1505 [ME Shils, JA Olson and M Shike, editors]. Philadelphia, PA: Lea and Febiger.

30. Poskitt EM, Cole TJ \& Lawson DE (1979) Diet, sunlight, and 25-hydroxy vitamin $\mathrm{D}$ in healthy children and adults. Br Med J 1, 221-223.

31. Nelson M, Naismith DJ, Burley V et al. (1990) Nutrient intakes, vitamin-mineral supplementation, and intelligence in British schoolchildren. Br J Nutr 64, 13-22.

32. Singh M (2004) Role of micronutrients for physical growth and mental development. Indian J Pediatr 71, 59-62.

33. Serra-Majem L, Ribas-Barba L, Perez-Rodrigo C et al. (2006) Nutrient adequacy in Spanish children and adolescents. Br J Nutr 96, Suppl. 1, S49-S57.
34. Kyttala P, Erkkola M, Kronberg-Kippila C et al. (2010) Food consumption and nutrient intake in Finnish 1-6-year-old children. Public Health Nutr 13, 947-956.

35. Lambert J, Agostoni C, Elmadfa I et al. (2004) Dietary intake and nutritional status of children and adolescents in Europe. Br J Nutr 92, Suppl. 2, S147-S211.

36. Ralston NVC \& Raymond LJ (2010) Dietary selenium's protective effects against methylmercury toxicity. Toxicology 278, 112-123.

37. van den Boom A, Serra-Majem L, Ribas L et al. (2006) The contribution of ready-to-eat cereals to daily nutrient intake and breakfast quality in a Mediterranean setting. $J \mathrm{Am}$ Coll Nutr 25, 135-143.

38. Food Standards Agency \& Department of Health (2010) National Diet and Nutrition Survey. Headline Results from Year 1 of the Rolling Programme (2008/2009). http://www. food.gov.uk/multimedia/pdfs/publication/ndnsreport0809. pdf (accessed October 2011).

39. Ferro-Luzzi A, Norgan NG \& Durnin JV (1975) Food intake, its relationship to body weight and age, and its apparent nutritional adequacy in New Guinean children. Am J Clin Nutr 28, 1443-1453.

40. Bovet P, Chiolero A, Madeleine G et al. (2010) Prevalence of overweight and underweight in public and private schools in the Seychelles. Int J Pediatr Obes 5, 274-278.

41. Cole TJ, Flegal KM, Nicholls D et al. (2007) Body mass index cut offs to define thinness in children and adolescents: international survey. BMJ 335, 194.

42. Bovet P, Chiolero A, Madeleine G et al. (2006) Marked increase in the prevalence of obesity in children of the Seychelles, a rapidly developing country, between 1998 and 2004. Int J Pediatr Obes 1, 120-128.

43. West KP (2003) Vitamin A deficiency disorders in children and women. Food Nutr Bull 24, 4 Suppl., S78-S90.

44. Hubbs-Tait L, Kennedy TS, Droke EA et al. (2007) Zinc, iron, and lead: relations to head start children's cognitive scores and teachers' ratings of behavior. J Am Diet Assoc 107, 128-133.

45. Sirot V, Dumas C, Leblanc JC et al. (2011) Food and nutrient intakes of French frequent seafood consumers with regard to fish consumption recommendations: results from the CALIPSO study. Br J Nutr 105, 1369-1380.

46. Food and Agriculture Organization of the United Nations (2001) The Composition of Fish. http://www.fao.org/ wairdocs/tan/x5916E/x5916e00.htm (accessed October 2011).

47. Livingstone MB \& Robson PJ (2000) Measurement of dietary intake in children. Proc Nutr Soc 59, 279-293. 